\title{
What kills us and what costs us
}

\section{An examination of the ALS Ice Bucket Challenge}

\author{
Keegan Guidolin (Meds 2017), Matthew Douglas-Vail (Meds 2018) \\ Faculty Reviewer: Dr Shannon L Venance, MD, PhD, FRCPC (Department of Clinical Neurological Sciences)
}

\section{DISEASE BURDEN: A CHANGING LANDSCAPE}

Over the 85 years this journal has been publishing, medicine has adapted to the changing landscape that is disease burden. In 1930 , the majority of diseases that medicine fought were infectious in nature. Influenza, pneumonia, tuberculosis, and gastrointestinal infections were the top killers. After 85 years of scientific advancement, infectious diseases have become well controlled in the developed world, and the population no longer fears these ailments. In 2015, different beasts threaten our lives-heart disease, cancers, and chronic airway diseases comprise the majority of our disease burden. ${ }^{1}$ Valar morghulis-all men must die. As medicine saved patients from acute conditions, they began living long enough to die from chronic diseases. As the disease burden shifted, so too did the attention and anxiety of the population, which in turn shifted one of the most important drivers of medical progress: funding.

\section{A FUNDING DISPARITY}

According to Jones and colleagues, the "goal [of medicine] should be an integrated policy under which health care and public health programs together fully address the disease burden,"1 This implies that funds should be allocated in proportion to the disease burden they represent; for example, since heart disease is the major contributor to disease burden in North America, it should receive the greatest amount of funding. However, this is not the case. According to the NIH, while heart disease causes more deaths than any other disease, in 2006 it received only 3.3\% of NIH funding (\$398 million), while HIV/AIDS, with a prevalence ten times lower, received seven times more ( $\sim 2.9$ billion).The funding disparity is pervasive: together, HIV/AIDS, diabetes mellitus, perinatal conditions, dementia, and alcohol abuse account for $49 \%$ of NIH research funds, but none of these conditions are listed in the top ten causes of mortality. ${ }^{2}$

\section{ALS ICE BUCKET CHALLENGE - A CASE IN POINT}

This funding disparity extends beyond government funding to publicly raised charity funding. The most recent example of a disconnect between disease burden and funding raised through charitable donation is the viral phenomenon of the ALS Ice Bucket Challenge. Amyotrophic lateral sclerosis (ALS), also known as Lou Gehrig's Disease for the baseball player who made it famous, is a progressive, incurable, neurodegenerative disorder causing muscle weakness and eventual death. It is the most common form of motor neuron disease and upon diagnosis, it has a median survival of 3-5 years. Prevalence rates range between 2.7 and 7.4 per 100000 across North America and Europe, with the disease being slightly more common in men (M:F ratio of 1.3-1.5:1). ${ }^{3}$
ALS recently made waves in the media through a viral fundraising campaign involving filming the dumping of a bucket of ice water on someone's head in an effort to promote awareness of ALS and subsequently raise money for research. Most videos end with a challenge to others to follow suit.

The phenomenon began in Florida in July 2014 when a local golfer, Chris Kennedy, was nominated to do the Ice Bucket Challenge or donate money to a charity that benefitted a local child with cancer. When Kennedy passed the challenge along, he chose a charity benefitting ALS because he had an afflicted relative. A video posted to YouTube on July 15, 2014 appears to be the first incidence of the Ice Bucket Challenge being connected to ALS. Through social media, the trend exploded and spread across countries and organizations. ${ }^{4}$

According to CBC, more than 260000 Canadians took part in the Ice Bucket Challenge and raised over $\$ 16.2$ million for ALS, $\sim \$ 10$ million of which will go directly to research, and $\sim \$ 6$ million of which will go to supporting those living with ALS. The Canadian government also contributed $\$ 10$ million to ALS. ${ }^{5}$ This is undoubtedly an impactful contribution but the Ice Bucket Challenge is wrought with issues.

Paradoxically, the usual challenge is to perform the Ice Bucket Challenge within 24 hours or make a charitable contribution to ALS, in other words allowing people to forego donation if they complete the challenge. Many people throughout the campaign raised concerns, especially since every video showing the challenge being completed seemed to imply that dumping cold water on your head is preferable to donating to ALS. Several individuals suffering from ALS have also spoken out that the campaign reduces a debilitating and lethal disease to a social bandwagon onto which people eagerly jump without any real regard for its purpose. ${ }^{6}$ However, there is a more worrisome issue at the heart of the ALS Ice Bucket Challenge.

According to Statistics Canada, the number of Canadians reporting charitable contributions on their income tax is decreasing (down 0.6\% from 2010 to 2011), suggesting that fewer people are donating money to charity. However, the rise in charitable contributions suggests that fewer people are donating more. Further, only $15 \%$ of Canadian donations are to healthcare organizations, amounting to $\$ 1.59$ billion. Charitable donations are affected by economic conditions such as the recent economic downturn, suggesting that the surge in funding for ALS may represent an equal decrease in contributions to all other healthcare charities. ${ }^{78}$ This opportunity cost is the most troubling aspect of the Ice Bucket Challenge. 
In 2011 (most recent data), 47627 Canadians died of heart disease, accounting for $19.7 \%$ of deaths, yet the Canadian Heart and Stroke Foundation received only $\$ 114.5$ million in fundraising donations, equivalent to approximately $\$ 2404$ per individual death., ${ }^{9,10}$ By comparison, between 700 and 1100 Canadians die of ALS each year, while the Ice Bucket Challenge alone (not counting donations outside of the challenge) raised $\$ 16.2$ million in Canada; equivalent to between $\sim \$ 16200$ and $\sim \$ 23150$ per individual who died.,11 Moreover, economic costs due to cardiovascular disease in Canada in 2000 totaled $\$ 22.2$ billion, representing $17 \%$ of all hospitalizations (2005-2006) and $10 \%$ of all visits to community physicians (2007). ${ }^{12}$ Contrast this with ALS, with an economic burden amounting to approximately $\$ 182$ million. ${ }^{13}$ The discrepancy between what kills us and what costs us, and where we donate is a costly one, in terms of both dollars and lives.

Of course, the question must be raised: if we divert funding to the most lethal and burdensome diseases, what becomes of the rare diseases like ALS? Research and treatment for rare diseases remains incredibly important, and funding is scarce by comparison to the major destinations of Canada's health research funds. The top disease groups funded by Canada's health research funding agency, the Canadian Institutes of Health Research, are cancer, diabetes, cardiovascular disease, and respiratory health, representing the major disease burden in Canada. ${ }^{14}$ This means that rare diseases like ALS need to be funded almost exclusively by charitable contributions. In fact, ALS Canada has successfully raised substantial amounts of money towards research. In 2013, over $\$ 3.8$ million was raised to support ALS research-a modest sum compared to the $\sim 16.2$ million raised by the Ice Bucket Challenge alone-however, one that is more in keeping with the proportional impact of ALS on the population. ${ }^{15}$

\section{CONCLUSIONS}

If we, as a society in Canada, wish to maximize the utility of our charitable donations, we might aim to be better informed as to what health problems are most pervasive and costly. The greater good of society should factor into decisions about where to direct charitable donations instead of relying solely on emotional or social motivations. Addressing this requires appropriate and balanced education. The recent ALS Ice Bucket Challenge phenomenon served as a great success for the fight against ALS, raising both money and awareness of the disease. However, it may represent a setback in the fight of society at large against the modern, chronic burden of disease. The goal is not to eliminate all funding for ALS, but rather to fund all diseases in proportion to their prevalence, economic cost, and mortality. A broad-minded society would attempt to erase the discrepancy between the diseases that kill us and cost us, and those which garner our attention. The final decision however, rests firmly in the hands of the donors.

\section{REFERENCES}

1. Jones DS, Podolsky SH, Greene JA. The burden of disease and changing task of medicine. N Engl J Med. 2012 Jun;366:2333-8.

2. Gillum LA, Gouveia C, Dorsey ER, Pletcher M, Mathers CD, McCulloch CE, Johnston SC. NIH disease funding levels and burden of disease. PLoS ONE. 2011 Feb;el6837.

3. Maragakis NJ, Galvez-Jimenez N. Epidemiology and pathogenesis of amotrophic lateral sclerosis. In: UpToDate, Shefner JM, Targoff IN, Dashe JF (Ed), UpToDate, Waltham, MA. (Accessed on January 28, 2015).

4. Sifferlin A. Here's how the ALS Ice Bucket Challenge actually started. [Internet]. New York (USA): TIME; 2014 [cited 2015 Jan 28]. Available from: http://time.com/3136507/als-ice-bucket-challenge-started/

5. CBC News. Ice Bucket Challenge raised \$16.2M for ALS in Canada. [Internet]. Toronto (Canada): CBC; 2014 [cited 2015 Jan 28]. Available from: http://www.cbc.ca/news/politics/ice-bucket-challenge-raised16-2m-for-als-in-canada-1.2840249

6. CBC News. Ice Bucket Challenge: charity success story or damaging fad? [Internet]. Toronto (Canada): CBC;2014 [cited 2015 Jan 28]. Available from: http://www.cbc.ca/newsblogs/yourcommunity/2014/08/ ice-bucket-challenge-charity-success-story-or-damaging-fad.html

7. Turcotte M. Charitable giving by Canadians. Can Soc Trends. 2012 Apr;11(008):16-36.

8. Lasby D. Trends in individual donations: 1984-2010. Research Bulletin. 2011 Dec;15(1):1-12.

9. Statistics Canada. Leading causes of death, by sex. [Internet]. Ottawa (Canada): Health Canada; 2014 [cited 2015 Jan 28]. Available from: http://www.statcan.gc.ca/tables-tableaux/sum-som/101/cst01/ hlth36a-eng.htm

10. Heart and Stroke Foundation of Canada. Consolidated financial statements. [Internet]. Ottawa (Canada): Heart and Stroke Foundation; 2014 [cited 2015 Jan 28]. Available from: http://www.heartandstroke. com/atf/cf/\%7B99452 d8b-e7fl-4bd6-a57d-bl36ce6c95bf\%7D/ HEART-AND-STROKE-CANADA-CONS-FS-F14.PDF

11. Noonan CW, White MC, Thurman D, Wong LY. Temporal and geographic variation in United States motor neuron disease mortality, 1969-1998. Neurology. 2005;64(7):1215.

12. Public Health Agency of Canada. 2009 Tracking heart disease and stroke in Canada report highlights. [Internet]. Ottawa (Canada): Public Health Agency of Canada; 2009 [cited 2015 Jan 28]. Available from: http://www.phac-aspc.gc.ca/publicat/2009/cvd-avc/report-rapport-eng.php

13. Canadian Institute for Health Information. The burden of neurological diseases, disorders and injuries in Canada. [Internet]. Ottawa (Canada): CIHI; 2007 [cited 2015 Jan 28]. Available from: https://secure.cihi. ca/free_product s/BND_e.pdf

14. Public Health Agency of Canada. Fact sheet Government of Canada chronic disease initiatives. [Internet]. Ottawa (Canada): Public Health Agency of Canada; 2011 [cited 2015 Feb 3]. Available from: http://www. phac-aspc.gc.ca/media/nr-rp/2011/2011_0919-fs-fr-eng.php

15. ALS Canada. 2013 annual report. [Internet]. Markham (Canada): ALS Canada; 2013 [cited $2015 \mathrm{Feb} 3$ ]. Available from: http://www.als.ca/ sites/de fault/files/files/ALS\%20Canada\%202013\%20Annual\%20Report_Layout\%201.pdf 